European Association for the

Development of Renewable Energies,

Environment and Power Quality (EA4EPQ)
International Conference on Renewable Energies and Power Quality (ICREPQ'11)

Las Palmas de Gran Canaria (Spain), 13th to 15th April, 2011

\title{
Performance and Efficiency of a Biogas CHP System Utilizing a Stirling Engine
}

\author{
Ahmad Pourmovahed, Ph.D. ${ }^{1}$, Terance Opperman ${ }^{2}$ and Brenda Lemke ${ }^{3}$ \\ ${ }^{1}$ Professor \\ Phone number: 810-762-9758, e-mail: apourmov@kettering.edu \\ ${ }^{2}$ Graduate Student \\ Phone number: 810-762-9500, e-mail: oppe7141@kettering.edu \\ ${ }^{3}$ Lecturer \\ Phone number: 810-762-9500 ext. 5833, e-mail: blemke@ kettering.edu \\ Mechanical Engineering Department \\ Kettering University \\ Flint, Michigan, 48504 U.S.A.
}

\begin{abstract}
A Stirling engine utilizes external combustion to produce heat and electricity. Due to the external combustion chamber, the engine can utilize a multitude of fuels including biogas or natural gas. The system used in this study is capable of producing about $7 \mathrm{~kW}$ of heat and $1 \mathrm{~kW}$ of electricity. Nitrogen is used as the "working fluid" in the engine. The heat from the combustion chamber is circulated through a cooling system making use of the thermal energy. The system includes a battery bank for energy storage and has been equipped with various instruments used to measure temperatures, pressures and flow rates of the fuel, the combustion air and the coolant. The engine is operated using natural gas as well as biogas and the engine characteristics for each are compared. The data collected is used to determine the system performance, thermal and electrical power outputs, individual and overall efficiencies, as well as exhaust emissions $\left(\mathrm{O}_{2}, \mathrm{CO}, \mathrm{CO}_{2}, \mathrm{NO}_{\mathrm{x}}\right.$ and $\left.\mathrm{HC}\right)$. This paper will present a detailed description of the CHP system, the instrumentation, the test procedures, the test data, analysis of the results and comparison of the biogas and natural gas test results.
\end{abstract}

\section{Key Words}

Stirling engine, CHP, Power Station, Biogas, external combustion, alternative fuels

\section{Introduction}

In 2010, Kettering University received a research grant from the United States Department of Energy (DOE) through the Michigan Economic Development Corporation (MEDC) to verify and improve process parameters for the production of biogas at the Flint Wastewater Treatment Plant and to determine the feasibility of utilizing biogas in transportation and power generation applications. A part of this project involved the selection, installation, instrumentation and testing of a Stirling engine combined heat and power (CHP) system. After considering numerous systems, a 24V DC WhisperGen Personal Power Station PPS16-24LG was selected, purchased and installed in the Automotive Laboratory at Kettering University.

One of the advantages of a Stirling engine is its external combustion. This allows the engine to run on a multitude of fuels where other engines cannot. The Stirling engine can be run on any fuel that will combust within the combustion chamber. These include gasoline, diesel, natural gas, propane, and biogas. Another advantage with the external combustion chamber is that the fuel does not have to be refined as it does for other types of engines. The external combustion also provides for more complete combustion resulting in less unburned hydrocarbons emitted in the exhaust.

One of the fuels we used for testing the Stirling engine was natural gas which is piped into the building from the local utility company. It consists of $96.4 \%$ methane, $1.5 \%$ ethane, $1.4 \%$ carbon dioxide, and trace amounts of nitrogen and propane.

The other fuel we used for our testing was biogas which consists of $62 \%$ methane, $37 \%$ carbon dioxide and $1 \%$ nitrogen (by volume). This blend of biogas is what the City of Flint Waste Water Treatment Plant will produce from their anaerobic digesters. Bio-methane is upgraded biogas and is close to natural gas in its composition and can be used in everyday applications. The Stirling engine can run on biogas which eliminates the need for further upgrading, process time and costs. 


\section{Brief History}

The Stirling engine was invented by Reverend Robert Stirling in 1816 as a safer alternative to the steam enigne. Due to the lack of material strength, steam engines were prone to frequently exploding and causing massive injuries to workers. The Stirling engine would not explode due to its low working pressures. The engine would simply stop if the combustion chamber failed. Eventually the Stirling engine began having the same material failures as the steam engine. As the quality of steel advanced, the steam engine became safer and the Stirling engine gradually disappeared. Figure 1 shows the WhisperGen Stirling engine CHP system used in this study.

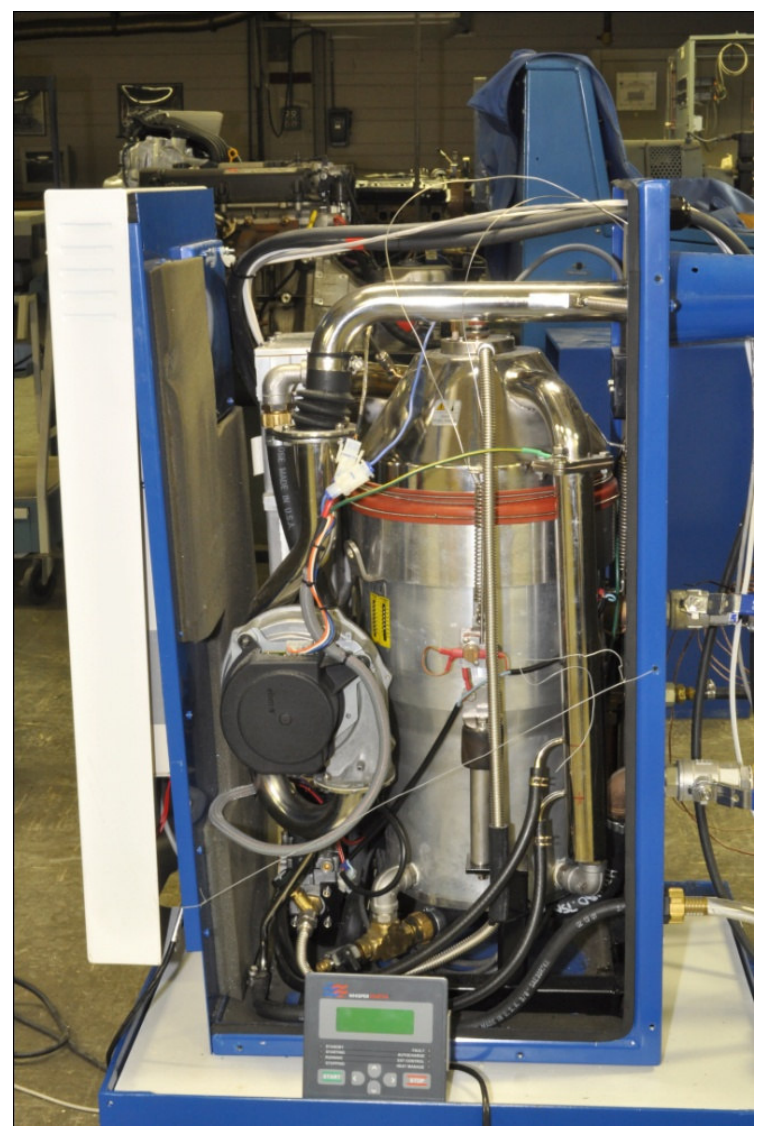

Fig. 1. The installed WhisperGen Stirling engine.

\section{Advantages of the Stirling Engine}

- Fuel Versatility: Can burn a variety of fuels such as biogas, methane, flare gas, synthetic gases, hydrogen, volatile organic compounds, or conventional gaseous fuels.

- Very low emissions: The constant combustion process in the Stirling engine destroys almost $100 \%$ of hydrocarbons and generates very low $\mathrm{NO}_{\mathrm{x}}$ and $\mathrm{CO}_{2}$ emissions without exhaust after-treatment.

- Combined Heat and Power: Generates both electrical power and hot water for maximum efficiency.
- Smooth and Quiet: Unlike traditional generators, the Stirling engine does not require vibration and sound attenuation.

- The Green Factor: The Stirling engine can consume renewable fuels and produces minimal emissions.

- Environmental benefits: reducing $\mathrm{CO}_{2}$ and other emissions.

- Low Maintenance: The combustion of a Stirling engine occurs outside the cylinders and hence there is no fuel or oil contamination within the engine. Stirling engines have about $50 \%$ fewer moving parts than internal combustion engines. This also means less wear with the result of reduced maintenance and no oil changes for the life of the unit.

- Real savings for the user through the production of their own electricity to supplement grid electricity supply.

- Economic benefits for utilities especially in helping to avoid peak-load costs when the public network is overloaded.

- Reduces the need for large central power stations and their associated transmission network

In spite of much effort in Stirling engine research especially in the 1970's and 80's, Stirling engines never became commercially available. The biggest reason why Stirling engines have not had a breakthrough are because of the superiority of the internal combustion engines. Until now, a Stirling engine has been only a niche product because of the high production costs. Nevertheless, Stirling engines are seen as eco-friendly engines with low emissions and noise and a high potential for future design concepts such as Combined Heat and Power Units (CHP).

In this field, there have been many efforts to develop commercially attractive versions, but until recently, Stirling engines have not been widely and commercially used as Combined Heat Power Units (CHP).

\section{Objectives}

The objectives of this study were to determine the power output and efficiencies of the Stirling engine CHP system. These were divided into thermal, electrical and overall categories. Another objective was to analyze the engine emissions by testing for oxygen $\left(\mathrm{O}_{2}\right)$, carbon monoxide $(\mathrm{CO})$, carbon dioxide $\left(\mathrm{CO}_{2}\right)$, nitrogen oxides $\left(\mathrm{NO}_{\mathrm{x}}\right)$ and unburned hydrocarbons (HC). As stated earlier, this was done while running the engine on natural gas and biogas as fuel. A comparison between the two fuels is made. 


\section{Values Used in Calculations}

Gas Specific Gravity for Natural Gas $=0.5807$ (compared to air)

Gas Specific Gravity for Biogas (62\% methane) = $\{(0.62 * 16)+(0.37 * 44)+(0.01 * 28)\} / 28.97=0.9141$ (compared to air)

Natural Gas density (at STP of 1.013 bar and $15^{\circ} \mathrm{C}$ ): 0.68 $\mathrm{kg} / \mathrm{m}^{3}$

Biogas density (at STP of 1.013 bar and $15^{\circ} \mathrm{C}$ ): $1.1 \mathrm{~kg} / \mathrm{m}^{3}$

Lower Heating Values:

LHV of Natural Gas $=34 \mathrm{MJ} / \mathrm{m}^{3}$ or $50 \mathrm{MJ} / \mathrm{kg}$

$\mathrm{LHV}$ of Biogas $=21 \mathrm{MJ} / \mathrm{m}^{3}$ or $19.1 \mathrm{MJ} / \mathrm{kg}$

Coolant: $50 \%$ water, $50 \%$ glycol

Specific Heat of water $=4.186 \mathrm{~kJ} /\left(\mathrm{kg}^{\circ} \mathrm{C}\right)$

Specific Heat of glycol $=2.36 \mathrm{~kJ} /\left(\mathrm{kg}^{\circ} \mathrm{C}\right)$

Specific Gravity of water $=1$

Specific Gravity of glycol $=1.1132$

\section{Thermal and Electrical Power}

The thermal and electrical power outputs of the Stirling engine are fractions of the fuel energy supplied to the engine. As expected, the power output for natural gas was higher than those for the biogas. This is due to the difference in the amount of combustible substances, methane, in the two different fuels, $96.4 \%$ and $62 \%$ respectively. Fig. 2 shows an initial sinusoidal pattern to the thermal energy.

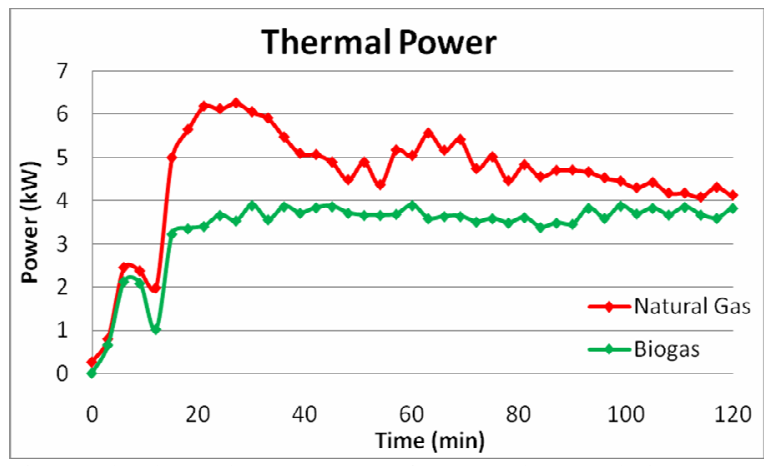

Fig. 2. The thermal power output for natural gas and biogas.

This is caused by the controller in the Stirling engine that monitors the exhaust temperature. With high exhaust temperatures, the controller will automatically adjust the air fan until the exhaust temperature drops below the set point of $480^{\circ} \mathrm{C}$. The controller will then again adjust the fan to ramp up the engine to full power. This process will continue and create the spikes as seen in the natural gas data.

Figure 3 indicates the same trend in the natural gas electrical power data. This is also due to the exhaust temperature controller. As will be seen in the following data, this peak and valley trend to the natural gas data will continue. It also shows up in the efficiency data as well as some of the emissions data.

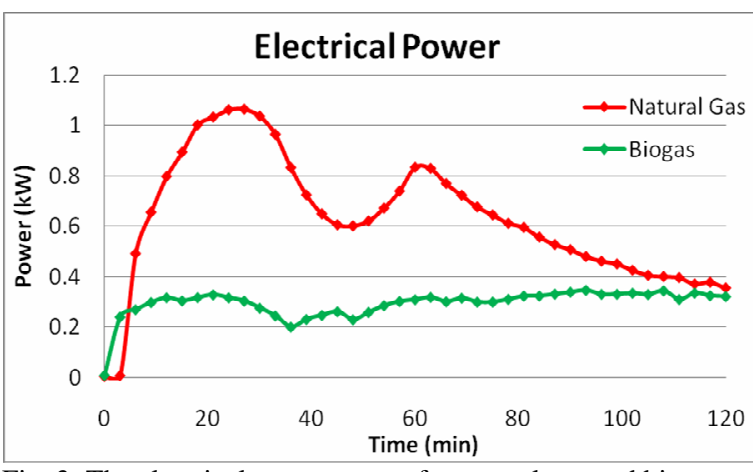

Fig. 3. The electrical power output for natural gas and biogas.

\section{Thermal and Electrical Efficiencies}

The thermal and electrical efficiencies of the Stirling engine are directly related to the power outputs. As expected, the thermal efficiency is much higher than the electrical efficiency. The WhisperGen CHP unit is specifically designed for producing more thermal output than electrical output. Higher electrical output units are available but are much larger and cost considerably more.

Fig. 4 shows that even though biogas has less energy as a fuel and produces less thermal output, the thermal efficiency remains the same.

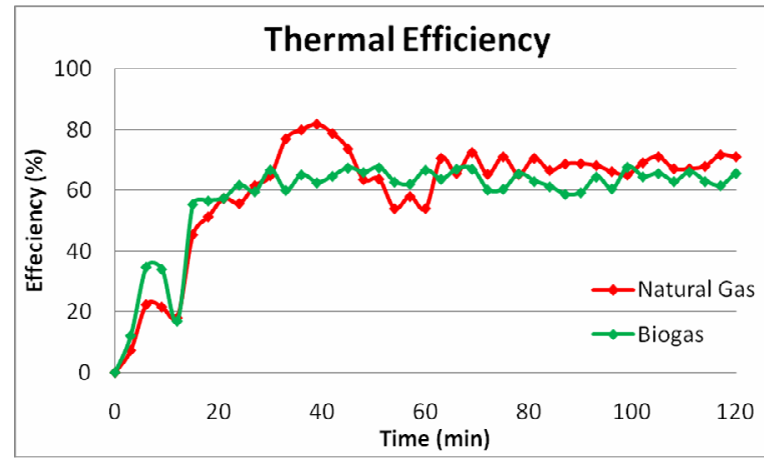

Fig. 4. The thermal efficiency for natural gas and biogas.

Fig. 5 shows the electrical efficiency of the CHP system for both natural gas and biogas.

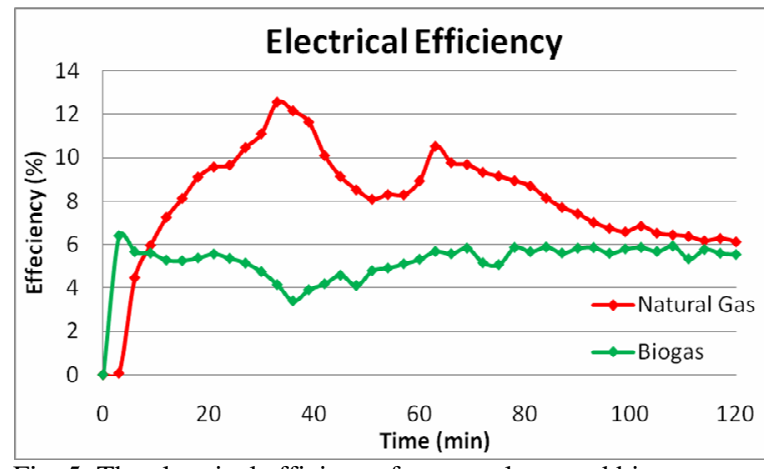

Fig. 5. The electrical efficiency for natural gas and biogas. 


\section{Emissions}

The main combustion products include $\mathrm{CO}_{2}, \mathrm{H}_{2} \mathrm{O}, \mathrm{N}_{2}$ and possibly $\mathrm{O}_{2}$. These products show up in the Stirling engine exhuast. Since natural gas is not pure methane and contains trace amounts of other compounds, there will also be other compounds in the emissions. For the most part, these compounds will appear in very low quantities. Due to the incomplete combustion of the methane there can be unburned hydrocarbons in the emissions. For biogas, nitrogen is present in the reactants and the products. It is said to be inert, non-reacting, and is not considered as an emission. Some of the nitrogen will combine with excess oxygen to form compounds in the form of $\mathrm{NO}_{\mathrm{x}}$. For the Stirling engine emissions a standard 5-gas analysis is adequate. A typical 5-gas analyzer measures concentrations of $\mathrm{CO}, \mathrm{CO}_{2}, \mathrm{O}_{2}, \mathrm{NO}_{\mathrm{x}}$, and $\mathrm{HC}$.

Fig. 6 shows the same peak and valley trend in the natural gas data as seen before.

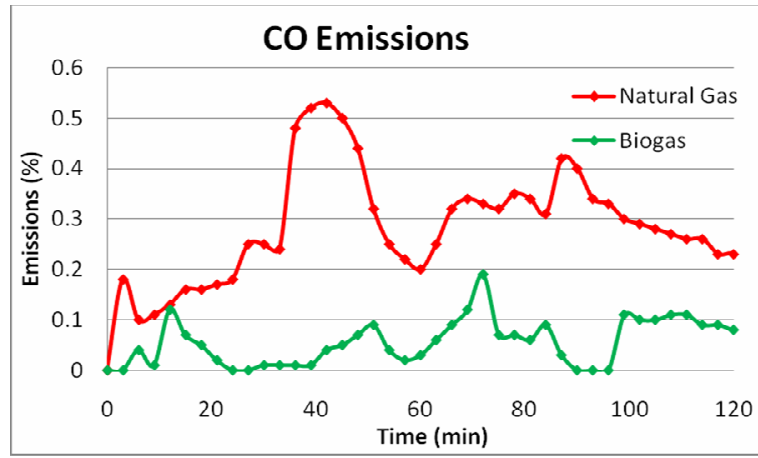

Fig. 6. Carbon monoxide emissions for natural gas and biogas.

Although the carbon monoxide emissions for both fuels are quite low, overall the emissions for the biogas are less than that of the natural gas. Fig. 7 also shows that carbon dioxide emissions for the biogas are less than that of the natural gas.

In fact, the only emission that is higher for biogas than natural is oxygen. This is shown in Fig. 8.

Oxygen is a key component of air and is not considered harmful to the environment. Fig. 9 shows the $\mathrm{NO}_{\mathrm{x}}$ emissions for both fuels. Once again, we see the spikes in the natural gas data.

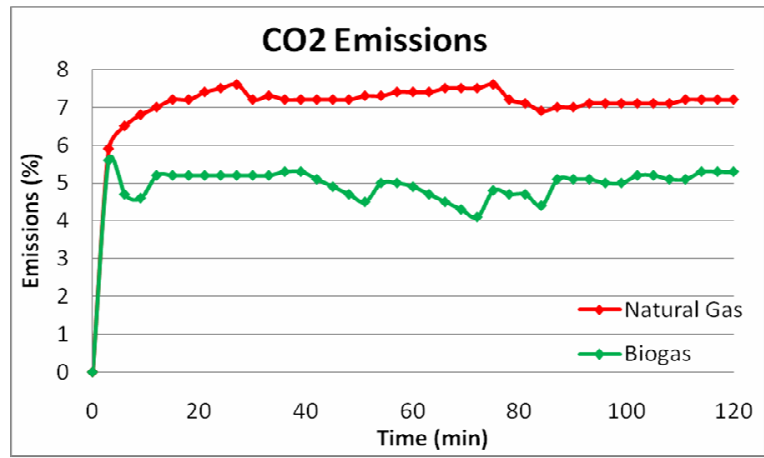

Fig. 7. Carbon dioxide emissions for natural gas and biogas.

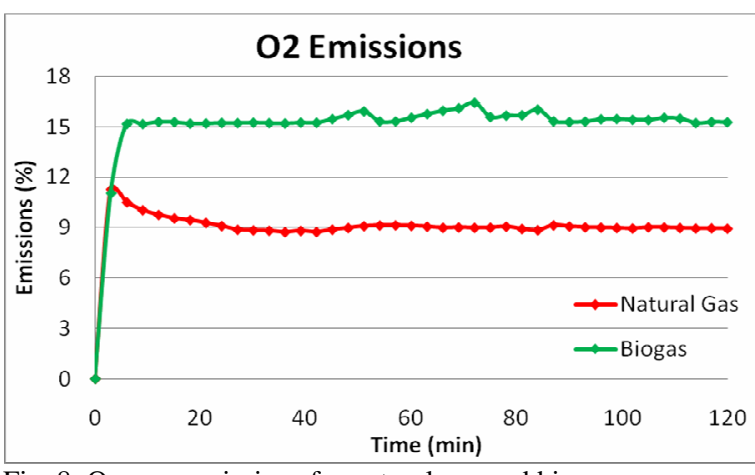

Fig. 8. Oxygen emissions for natural gas and biogas.

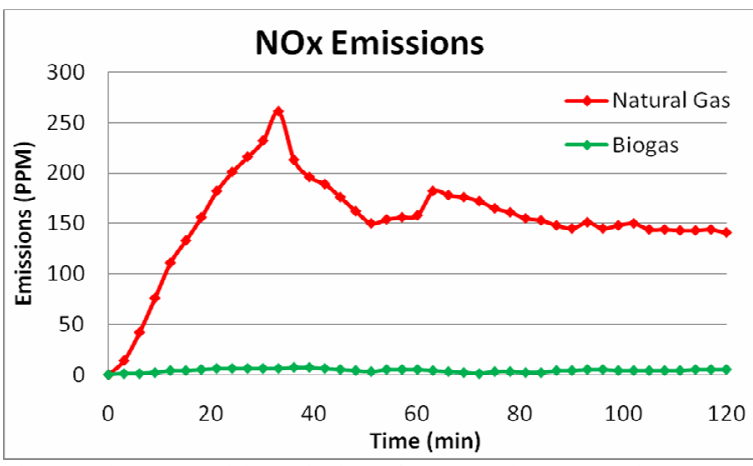

Fig. 9. Nitrogen oxide emissions for natural gas and biogas.

It also shows that the nitrogan oxide emissions for biogas is considerably less than that for natural gas. Since a major reason for changing to alternative fuels is to lower harmful emissions, this data clearly shows that using biogas instead of natural gas will lower the emissions of carbon monoxide, carbon dioxide and nitrogen oxide.

The only one of the emissions that could not be tested was the unburned hydrocarbons, in this case, methane. Using the gas analyzer for testing, it was noticed that the $\mathrm{HC}$ emissions values were very erratic. Upon further testing, it was concluded that there was a problem with the HC sensor in the gas analyzer. It has since been returned to the manufacturer for repairs.

\section{Combustion and Air/Fuel Ratio}

The complete combustion process requires a fuel and an oxidant, usually air. The products of combustion are typically carbon dioxide, water and nitrogen. Since air is approximately $79 \%$ nitrogen and $21 \%$ oxygen, the ratio is $79 / 21=3.76$ which means that for every one $\mathrm{Kmol}$ of oxygen in air there is $3.76 \mathrm{Kmol}$ of nitrogen.

A. Combustion of Methane:

$$
\begin{gathered}
\mathrm{CH}_{4}+\mathrm{X}\left(\mathrm{O}_{2}+3.76 \mathrm{~N}_{2}\right) \rightarrow \\
\mathrm{CO}_{2}+2 \mathrm{H}_{2} \mathrm{O}+(\mathrm{X}-2) \mathrm{O}_{2}+(3.76 \mathrm{X}) \mathrm{N}_{2}
\end{gathered}
$$

Since emissions are measured on a "dry" basis:

$$
X=\frac{\% O 2-2}{4.76(\% O 2)-1}
$$


For stoichiometric combustion: $\% \mathrm{O}_{2}=0$, thus $\mathrm{X}=2$

B. Stoichiometric A/F Ratio of Methane:

$$
\frac{A}{F}=\frac{(2 * 32)+(2 * 3.76 * 28)}{12+4}=17.16
$$

C. Actual A/F Ratio for Methane:

$$
\frac{A}{F}=\frac{8.58 *(2-\% O 2)}{1-4.76 *(\% O 2)}
$$

For example, if there is $5 \%$ Oxygen in the exhaust, $\% \mathrm{O}_{2}=$ 0.05 and $\mathrm{A} / \mathrm{F}=21.96$

D. Combustion of Biogas:

$\left(0.62 \mathrm{CH}_{4}+0.37 \mathrm{CO}_{2}+0.01 \mathrm{~N}_{2}\right)+\mathrm{X}\left(\mathrm{O}_{2}+3.76 \mathrm{~N}_{2}\right) \rightarrow$ $0.99 \mathrm{CO}_{2}+0.31 \mathrm{H}_{2} \mathrm{O}+(\mathrm{X}-0.775) \mathrm{O}_{2}+(3.76 \mathrm{X}+0.01) \mathrm{N}_{2}$

$$
X=\frac{0.225(\% 02)+0.775}{1-4.76(\% 02)}
$$

For stoichiometric combustion: $\% \mathrm{O}_{2}=0$, thus $\mathrm{X}=0.775$

E. Stoichiometric A/F Ratio of Biogas:

$\frac{A}{F}=\frac{(0.775 * 32)+(0.775 * 3.76 * 28)}{(0.62 * 16)+(0.37+44)+(0.01 * 28)}=4.02$

F. Actual A/F Ratio of Biogas:

$$
\frac{A}{F}=5.184 * X
$$

For example, if there is $5 \%$ Oxygen in the exhaust, $\% \mathrm{O}_{2}=$ 0.05 and $\mathrm{X}=1.032$. Thus $\mathrm{A} / \mathrm{F}=5.35$

The air/fuel ratios were calculated from the percentage of oxygen emissions from the exhaust. See equations (2) and (4) above. Fig. 10 shows that the A/F ratio for natural gas is near double that for biogas.

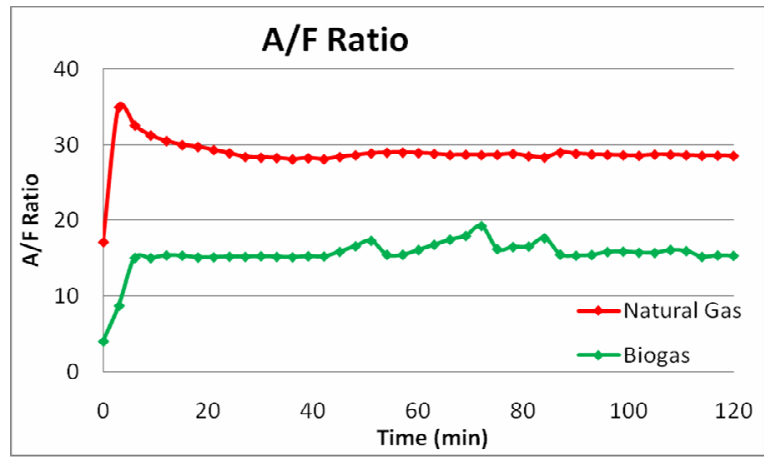

Fig. 10. The air/fuel ratio for natural gas and biogas.

This was to be expected since the stoichiometric $\mathrm{A} / \mathrm{F}$ ratio for natural gas is over four times greater than that for biogas, 17.16 and 4.02 respectively. Figure 11 shows the
A/F ratio versus $\mathrm{O}_{2}$ concentrations in the exhaust based on calculations using Equations 1-4.

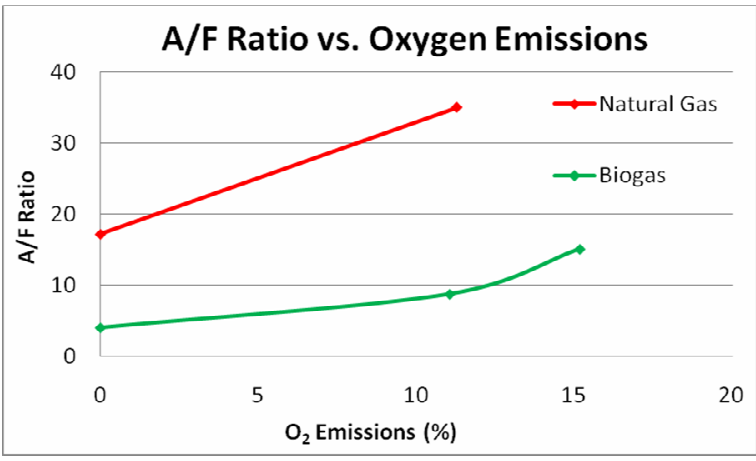

Fig. 11. The air/fuel ratio vs. $\mathrm{O}_{2}$ emissions.

\section{Conclusions}

The WhisperGen CHP unit was originally designed to run on gasoline or diesel fuel, but with few modifications we successfully used natural gas and unrefined biogas. We also ran the engine on propane. It is very clear that the Stirling engine will, or easily could be modified to, run on almost any fuel source. The unit also ran very quietly making its application for homes, cabins, or even boats very acceptable.

As expected, the energy output when using biogas as a fuel was less than that for natural gas. This is due to the fact that biogas has less combustible material, methane, thus less heat is released by the fuel.

We initially espected that the $\mathrm{CO}_{2}$ and possibly $\mathrm{CO}$ emissions would be higher when using biogas as a fuel compared to natural gas. This is because the biogas contains $37 \% \quad \mathrm{CO}_{2}$ where natural gas has only trace amounts. With that much $\mathrm{CO}_{2}$ going into the engine, we anticipated more $\mathrm{CO}_{2}$ coming out of the engine. With the Stirling engine running on biogas, the combustion temperature was less than $1200^{\circ} \mathrm{F}\left(650^{\circ} \mathrm{C}\right)$. The $\mathrm{CO}_{2}$ was assumed to be inert, thus appearing in the emissions. The experimental data shows that the $\mathrm{CO}_{2}$ and $\mathrm{CO}$ emissions for biogas were less than that for natural gas.

The WhisperGen Stirling Engine CHP system has been implemented in The Bio and Renewable Energy Laboratory course at Kettering University and is used by Mechanical Engineering students. It has proven to be an excellent educational tool.

\section{Issues}

During the course of testing we learned of several issues that need to be adressed.

One issue we discovered during the testing was the inconsistnat pattern in the natural gas data. As discussed earlier, the oxygen emissions for natural gas were quite low, less than $10 \%$. This means that the engine was running somewhat lean causing the exhaust temperature to become high, over $500^{\circ} \mathrm{C}$. Due to an internal controller, the WhisperGen software will automatically 
adjust the engine to reduce the exhaust temperature. The change in air flow to the engine affected the thermal and electrical power outputs, efficiencies, and emissions. In order to correct this, the exhaust temperature must be kept lower than the set-point. This is done by adjusting the air/fuel ratio to change the amount of oxygen emissions. The percentage of oxygen in the exhaust will be set to 10$12 \%$.

Another issue discovered during the testing was the bad $\mathrm{HC}$ sensor in the gas analyzer we used. The analyzer is currently being repaired. We plan to perform additional tests during which $\mathrm{HC}$ conentrations in the exhaust will be measured.

\section{Further Testing}

Once the above issues are addressed, the tests using natural gas and biogas will continue.

The first issue to be adressed is the erratic behavior in the natural gas data. It is predicted that this problem can be solved by adjusting the air/fuel ratio. Further testing will be required to prove this.

It will be interesting to see how much the thermal and electrical power output data will vary once the air/fuel ratios are reset to a more reasonable value. It is still projected that biogas will produce less power but how much less with the engine running at optimal efficiency for each fuel has yet to be seen.

Since the gas analyzer had a bad HC sensor, we currently have no $\mathrm{HC}$ emissions data. We are very interested in the amounts of $\mathrm{HC}$ emissions for each fuel. Again we are expecting less for biogas than for natural gas since less of the fuel is actually methane.

Adjusting the air/fuel ratio will affect all emission levels but it is not clear by what extent. Chemistry can give us a good glimpse into what to expect, but it will be good to verify those results with testing.

\section{Acknowledgements}

This research project was funded by the Biogas Center of Energy Excellence grant from the United States Department of Energy (DOE) through the Michigan Economic Development Corporation (MEDC). The authors are also grateful to the Swedish Biogas International and the City of Flint, Michigan for their support.

\section{References}

[1] Moran, M., Shapiro, H., (1996), Fundamental of Engineering Thermodynamics, Wiley.

[2] West, Colin D., (1986), Principles and Applications of Stirling Engines, Van Nostrand Reinhold Co.

[3] Walker, G., (1980), Stirling Engines, Clarendon Press.
[4] Stirling Technology, (2007), Retrieved August 11, 2010 from: www.whispergen.com

\section{Appendix}

A video of this CHP System at Kettering University can be watched at: http://www.kettering.edu/futurestudents/undergraduate/st irling_engine_demo_video.jsp

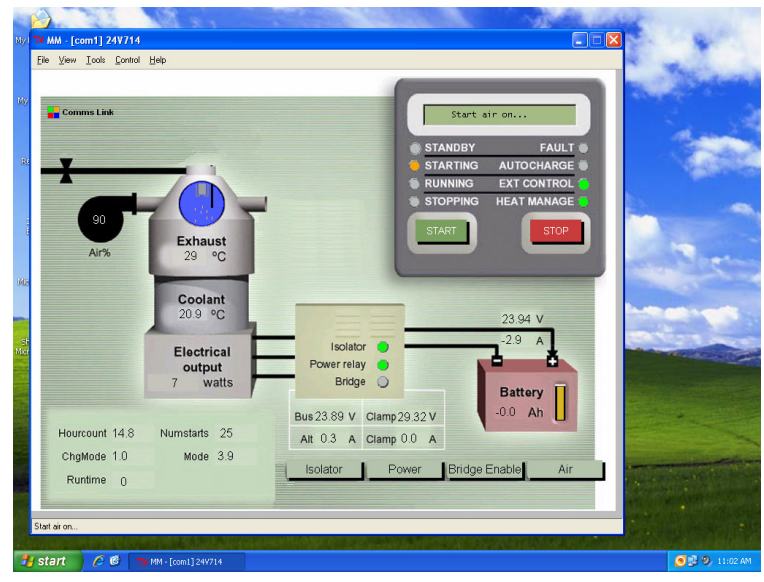

The data acquisition system graphic user interface

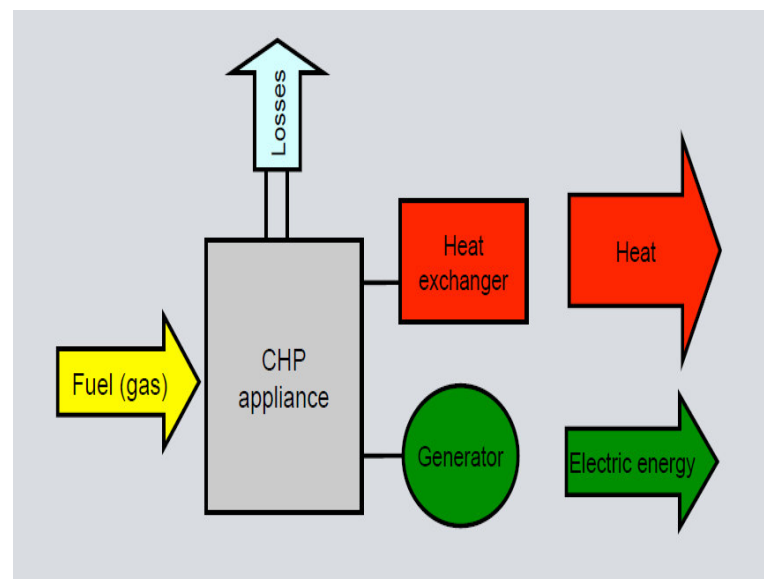

System energy flow (graphic courtesy of WhisperGen)

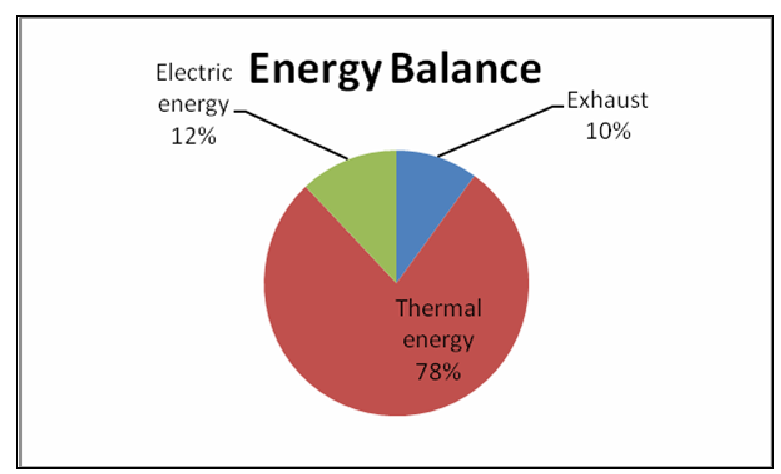

Typical energy balance pie chart when using natural gas 